\title{
Determining the Layout Parameters of the Gas Drainage Roadway: A Study for Sima Coalmine China
}

\author{
Zhiliu Wang, ${ }^{1}$ Bo Liu $\mathbb{D}^{2,3}$ Yanhui Han, ${ }^{4}$ Zhaoyang Li, ${ }^{2}$ Yingjie Cao, ${ }^{2}$ and Fuzhou Qi \\ ${ }^{1}$ School of Civil \& Architecture Engineering, Zhongyuan University of Technology, Zhengzhou 450007, Henan, China \\ ${ }^{2}$ School of Mechanics \& Civil Engineering, China University of Mining and Technology, Beijing 100083, China \\ ${ }^{3}$ State Key Laboratory for Geomechanics and Deep Underground Engineering, Beijing 100083, China \\ ${ }^{4}$ Department of Civil Environmental and Geo-Engineering, University of Minnesota, Minneapolis, MN, USA \\ Correspondence should be addressed to Bo Liu; 996056302@qq.com
}

Received 7 April 2021; Accepted 28 May 2021; Published 9 June 2021

Academic Editor: Dawei Yin

Copyright ( $) 2021$ Zhiliu Wang et al. This is an open access article distributed under the Creative Commons Attribution License, which permits unrestricted use, distribution, and reproduction in any medium, provided the original work is properly cited.

\begin{abstract}
To determine the layout parameters of the gas drainage roadway (GDR) serving for the working face, an analytical calculation method of fracture zone and the modelling experiment were adopted, and the overburden fissure induced by mining and the height of fracture zone were analyzed. For the research on the distribution of fracture zone by analytical calculation method, the multiple factors influencing the failure mode of strata and the height of fracture zone were considered. The \#1207 working face in Sima mine was taken as an engineering background, and the layout parameters of GDR were given by analyzing the height of fracture zone. Combining the results obtained by analytical calculation and scale modelling experiment, the suggested height of GDR was $10.7-32.8 \mathrm{~m}$ away from the coal seam roof, and the projection distance of GDR in the horizontal was within the range of 0-35 $\mathrm{m}$ from the airway. By monitoring the gas drainage effects in different heights away from coal seam roof in \#1207 working face and in different horizontal distances away from the ventilation roadway in the \#1211 working face, the results showed that the optimal height was 17.5-22 $\mathrm{m}$ away from coal roof, and the optimal horizontal distance was 17-21 $\mathrm{m}$ away from airway for GDR. The gas drainage effect of GDR indicated that the proposed parameters are scientific and reasonable.
\end{abstract}

\section{Introduction}

The production conditions of many mines in China are extremely complicated, and various major production accidents occurred $[1,2]$. Gas is one of the biggest disaster factors that lead to the production accidents $[3,4]$. The technology of gas drainage and relieved methane is an effective and reliable method for gas disaster treatment in high gas working face [5-10]. Currently, gas drainage roadway (GDR) is widely used in the gas drainage method, which can effectively solve the gas transfinite problem and make full use of the extracted gas. The layout parameters of the GDR directly affect the gas drainage effect [11]. When the layer of the GDR is too high, the problem of high gas in the working face cannot be solved. When the layer is too low, it is susceptible to seam mining and detrimental to the stability of the GDR.

Some researchers [12-14] thought that gas drainage should be firstly applied to transform high gas content coal seams into low gas content coal seams for the safety and effectivity of coal mining, the influence of different coal rock occurrence conditions on the three-zones was analyzed, and the calculation method for the height of the three zones was obtained [15]. Numerical simulation mode was built, and the characteristics of gas occurrence were given in the three zones above the goaf $[16,17]$. Wang et al. and Cheng et al. $[18,19]$ discussed in detail the arrangement of drainage roadway for gas extraction and proposed the methods for improving permeability of the first-mined and adjacent seams and constructing a gas tunnel. $\mathrm{Lu}$ et al. and $\mathrm{Li}$ et al. $[20,21]$ insisted that the extraction system should be arranged in the mining-induced fracture elliptic paraboloid zone, and the research result was successfully applied in different mines. Yuan et al. [22] gave the reasonable parameters of the GDR in some mines of Huainan. At present, most scholars analyzed the layout of the GDR based on the distribution of fracture zone. On the one hand, they analyzed 
the fracture zone of the surrounding rock from the aspects of numerical and physical simulation. On the other hand, analytical calculations were carried out by using empirical formula to obtain the height of the fracture zone.

In generally, the calculation of the fracture zone using the empirical formula is only related to the mining height and looseness coefficient of the coal seam [23]. In the process of working face mining, the height of the fracture zone of the overburden is also related to mining range, the distance between the key layer and the coal seam, and the movement characteristics of the key layer, which have been proved by field monitoring [24-26]. However, there are little analytical calculations and scale-modelling experiments for the height of the fracture zone considering the multiple influence factors, which makes it difficult to determine layout parameters of the GDR. The breather fracture field is located at the saddle shape profile, and it is in the range of the fracture zone, whose distribution is shown in Figure 1. The gas drainage roadway is placed in the fracture zone on the air-return roadway side of the working face, which is in favor of improving the gas drainage effect.

In the field, both gas drainage effect and the stability of gas drainage roadway should be taken into account. Thus, it is essential to calculate the range of fracture zone and determine the layout parameters of gas drainage roadway considering the multiple influence factors by analytical calculation method of fracture zone and the scale modelling experiment. In the work, an analytical calculation and a scale modelling experiment are adopted to determine the layout parameters of the GDR. Subsequently, the position parameters of the GDR are optimized based the measuring data in the Sima mine.

\section{Engineering Background of the Case}

The primitive gas content of the \#3 coal seam of Sima mine is $6.31 \mathrm{~m}^{3} / t$, and the desorption gas volume is $4.55 \mathrm{~m}^{3} / t$. The max absolute gas emission during production is $33.71 \mathrm{~m}^{3} /$ min. Due to the limitation of mine air volume, gas emission seriously affects the normal production. Thus, it is essential to conduct gas drainage. The GDR could be used in the working face to control gas for the first time. However, how to reasonably design the parameters of the GDR has become a key problem. The coal thickness is $6.3 \mathrm{~m}$, the inclined length is $199.5 \mathrm{~m}$, and the advancing length is $118.5 \mathrm{~m}$ in \#1207 working face. The gas drainage is mainly by drilling in the working face and in the fracture zone. The service intake roadway is located in the east of working face, and the maiden field is located in the north and west. The GDR is arranged in \#1207 working face for the first time, and the distribution of working face is shown in Figure 2.

In order to solve the abovementioned problem, the layout parameters of the GDR are studied by analytical calculation method of fracture zone and the scale modelling experiment. Multiple influence factors are considered in the analytical calculation method including mining range, the distance between key stratum and coal seams, and the movement of key stratum. Meanwhile, the

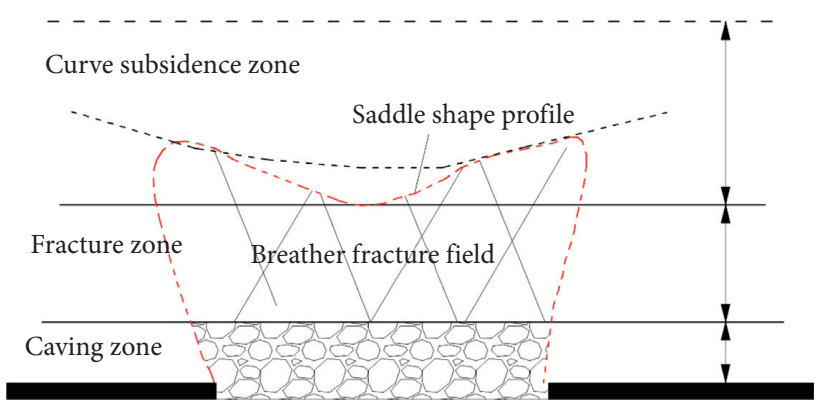

FIGURE 1: Distribution of saddle shape profile.

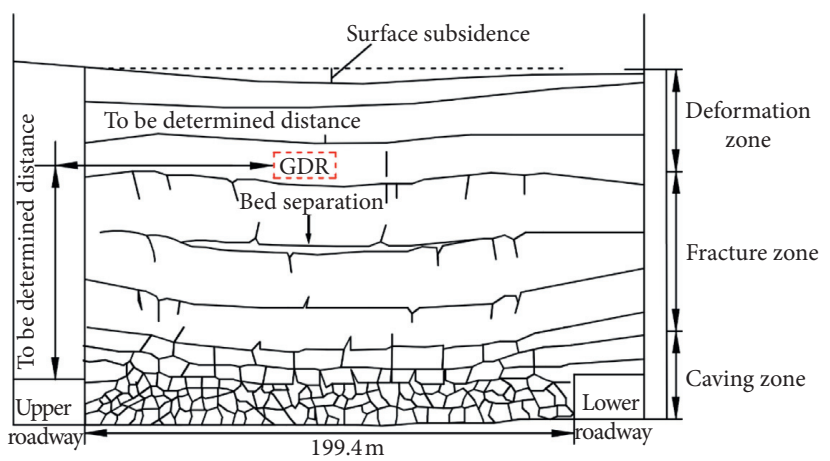

FIGURE 2: Distribution of working face.

engineering application is analyzed to optimize the layout parameters of the GDR.

\section{Analytical Calculation}

The partition of the fracture zone of overlying rock is not only related to the mining height of coal seam, but also affected by multiple factors such as the mining range in the working face, the strength of rock strata, the movement of the key layers, and the follower layers. Wang et al. [27] proposed a new method to calculate the height of fracture zone by considering the height of water flowing fracture zone under multiple factor action. The method thought that the goaf could not be completely filled with the loose and fractured rock mass and the key layer and the movement characteristics of rock mainly affected the fracture zone. With increasing mining range of coal seam, the fracture of key layer occurs when the hanging steps reach the limit value. After the fracture of key layer, it is by analyzing whether a hinge structure can be formed to judge that the overlying strata are a caving zone or fracture zone. If the rock layers form a hinge structure, the overlying strata are a fracture zone. If the rock layers cannot form a hinge structure, the overlying strata are a caving zone. The key stratum and its overlying strata can be considered as curve subsidence zone, when the key layer is not affected by coal mining, or the fracture does not appear within the working face. Based on the above new partition method of fracture zone, the height of fracture zone in \#1207 working face of Sima mine is calculated to provide support for the layout parameters of GDR.

The detailed calculation process is as follows: 
The 1st step: according to the identification method of key strata [28], there are five hard strata in the overburden strata of working face, among which there are three key strata. The first inferior key stratum is mudstone layer, which is $10 \mathrm{~m}$ away from coal roof. The second inferior key stratum is siltstone layer, which is $39.3 \mathrm{~m}$ away from coal roof. The main key stratum is fine-sandstone layer, which is $54.9 \mathrm{~m}$ away from coal roof.

The 2nd step: based on the fact that the parameters of the thickness of coal seam $(M)$, the thickness of immediate roof $\left(h_{1}\right)$, and residual expansion rate of rock $\left(k_{p}^{\prime}\right)$ meet the following equation, it is thought that the cavitation below the immediate roof can be formed:

$$
h_{1}+M \geq k_{p}^{\prime}\left[h_{1}+(1-C) M\right] \text {, }
$$

where $C$ is the recovery ratio, and its value is 0.97 . Meanwhile, the value of $M$ is $6.3 \mathrm{~m}$, the value of $h_{1}$ is $2.5 \mathrm{~m}$, and the value of $k_{p}^{\prime}$ is 1.30 .

The 3rd step: equation (2) is used to judge whether the fracture of the upper key strata can take place. If the mining parameters meet the following equation, the fracture will occur:

$$
a-2 \sum h \cot \alpha \geq h_{2}\left(\frac{2 R_{t}}{q}\right)^{1 / 2}
$$

where $a$ is the length of working face; $\sum h$ is the gross thicknesses between key strata and working face; $\alpha$ is the fracture angle of overlying strata; $h_{2}$ is the thicknesses of key strata; $R_{\mathrm{t}}$ is the tensile strength of key strata; and $q$ is the load of key strata. The calculation results of $a-2 \sum h \cot \alpha$ and $h_{2}\left(2 R_{t} / q\right)^{1 / 2}$ are listed in Table 1.

It can be seen from Table 1 that the values of $a-$ $2 \sum h \cot \alpha$ are all much larger than those of $h_{2}\left(2 R_{t} / q\right)^{1 / 2}$ for the three key layers, which indicates that the three key layers will be affected by the mining process, and the fracture of three key layers will occur.

The 4th step: to further determine whether the rock is a caving zone or a fracture zone after disrupting, the principle of "three hinged arch" is applied [29].

The conditions for fault rock blocks without slip and instability are given in

$$
\frac{h_{2}}{L} \leq 0.5 \tan \varphi,
$$

where $\varphi$ is the friction angle of rock, ${ }^{\circ} L$ is the fracture length, $\mathrm{m}$.

The conditions for fault rock without deformation and instability are presented in

$$
\begin{aligned}
& \frac{\sigma_{p}}{\sigma_{c}} \leq k, \\
& \sigma_{p}=\frac{2 q i^{2}}{(1-i \sin \beta)^{2}},
\end{aligned}
$$

TABLE 1: Calculation results.

\begin{tabular}{lcc}
\hline Key strata & $a-2 \sum h \cot \alpha$ & $h_{2}\left(2 R_{t} / q\right)^{1 / 2}$ \\
\hline First inferior key stratum & 1107.87 & 12.24 \\
Second inferior key stratum & 1074.59 & 24.56 \\
Main key stratum & 1068.84 & 32.30 \\
\hline
\end{tabular}

where $\sigma_{p}$ is the extrusion stress of occlusal area, $\mathrm{kPa} ; \sigma_{c}$ is the compressive strength of rock, $\mathrm{kPa} k$ is the proportional coefficient, and its value is 0.29 based on experience [30]; $\beta$ is the allowed angle of subsidence, which is determined by the cavitation size $\Delta$ and the fracture length $L$ [29]. $i$ can be obtained by

$$
i=\frac{L}{h_{2}}
$$

As displayed in Tables 2 and 3, only the first inferior key stratum cannot meet equations (3) and (4) at the same time.

To summarize, the mining thickness of coal seam is $6.3 \mathrm{~m}$, and there are key strata above the coal. The first inferior key stratum is fractured during mining process and then destabilized. The first inferior key stratum and its following stratum belong to caving zone, and the height of caving zone is $17 \mathrm{~m}$. The second inferior key stratum and main key stratum are also fractured during coal mining, but they can form hinge structure. Because the thickness of primary recovery is smaller, and the strata thickness below the main key layer is larger, the goal can be completely filled by the fracture rocks. Thus, the main key layer and its above rock strata are identified as curve subsidence zone, and the height of fracture zone is $44.2 \mathrm{~m}$.

According to the analytical calculation results above, the GDR was preferably arranged in the height range of 10.7 to $54.9 \mathrm{~m}$ from the coal seam roof to optimize the gas drainage effect. The distribution of fracture zone is shown in Figure 3.

\section{Scale Modelling Experiment}

In order to verify the rationality of the above theory analysis and study the layout parameters of the GDR in the working face, we take the \#1207 working face of Sima mine as the prototype to carry out scale modelling experiment.

The actual height of coal seam and its above rock strata is $380 \mathrm{~m}$. The scale model before excavation is shown in Figure 4. The length of model is $2400 \mathrm{~mm}$, and the height is $1200 \mathrm{~mm}$. In order to eliminate boundary effect, the excavation area is $1800 \mathrm{~mm}$ in the middle, leaving $300 \mathrm{~mm}$ on both sides as the boundary.

With the advance of working face, the TDS303 data collector was used to collect the pressure data of working face and the vertical displacement data of the upper part of the model. Meanwhile, the electronic theodolite was used to observe the angle variation of measuring points. The fracture angles in the mining side and in the open-off cut side are analyzed when the working face is advanced to $60 \mathrm{~cm}, 90 \mathrm{~cm}$, $120 \mathrm{~cm}, 150 \mathrm{~cm}$, and $180 \mathrm{~cm}$, respectively. The statistical results of fracture angle are shown in Table 4. 
TABLE 2: Calculation results.

\begin{tabular}{lcc}
\hline Key stratum & $h_{2} / L$ & $1 / 2 \tan \phi$ \\
\hline First inferior key stratum & 0.57 & 0.35 \\
Second inferior key stratum & 0.14 & 0.34 \\
Main key stratum & 0.24 & 0.43 \\
\hline
\end{tabular}

As shown in Table 4, the maximum and minimum values of fracture angle in the mining side are $64^{\circ}$ and $58^{\circ}$, respectively. The average value of fracture angle in the mining side is $61.6^{\circ}$. The maximum and minimum values of fracture angle in the open-off cut side are $67^{\circ}$ and $65^{\circ}$, respectively. The average value of fracture angle in the open-off cut side is $66^{\circ}$. The fracture angle in the mining side fluctuates greatly, while the fracture angle in the open-off cut side is relatively stable. Thus, it is estimated that fracture angle in the mining side is about $62^{\circ}$ and the fracture angle in the cut-off side is about $66^{\circ}$ for the $\# 1207$ working face of Sima mine based on the scale modelling experiment. The fracture angle in the mining side is always less than that in the cut-off side.

Based on the law of overburden movement during the excavation process, the fracture zone was divided, and the results are shown in Figure 5.

According to the obtained height of fracture zone in the physical similarity model and the geometrical similarity ratio between the actual strata and similarity model, it can be found that the height of the caving zone in \#1207 working face is $10.7 \mathrm{~m}$, and the height of the fracture zone is $44.2 \mathrm{~m}$. The curve subsidence zone is located over $54.9 \mathrm{~m}$ above the coal seam.

\section{Layout Parameters of the GDR and Field Application}

5.1. Layout Parameters of the GDR. The layout parameters of the GDR could be obtained by analytical calculation and scale modelling experiment. The GDR should be arranged in the most concentrative region of fractures. Based on the results of analytical calculation and scale modelling experiment, the layout parameters of the GDR in Sima mine are determined as follows:

(1) Layout parameters in the height direction

The maximum height of the GDR should be the upper limit of the fracture zone. Meanwhile, the GDR cannot be arranged in the range of the caving zone considering the maintenance of the roadway. It is found that the distribution of gas fissures tends to be closer to the lower part of fracture zone in Figure 1. Thus, the layout position of the GDR in the height direction is located in the middle and lower part of the fracture zone considering all factors. Reasonable layout of the GDR in the height direction is $10.7-32.8 \mathrm{~m}$ away from the coal roof.

(2) Layout parameters in the direction of parallel coal seams

A-A profile of the \#1207 working face of Sima mine in China is taken as the prototype of this study
(Figure 6). The GDR is mostly parallel to the roadway direction. In order to optimize the parameters of the GDR, the section transformation is performed. The collapse state of A-A section is the closest to the state of the B-B section when the goaf reaches a square distribution, and advancing distance of the working face is equal to the working face length. When the advancing length of working face is $200 \mathrm{~m}$, A-A profile is selected as a reference for the B-B profile, and the relevant parameters are analyzed to determine the parameters of the section transformation in the horizontal direction. When the working face advanced $200 \mathrm{~m}$, the excavation length of corresponding model is $100 \mathrm{~cm}$. The fracture angle in the mining side is $62^{\circ}$ and it is $66^{\circ}$ in the open-off cut side. According to the relevant standard, the reasonable layout area of the GDR is within $1 / 3$ length of the working face near ventilation roadway. The length of the \#1207 working face is $200 \mathrm{~m}$, and the reasonable area of the GDR is from $0 \mathrm{~m}$ to $70 \mathrm{~m}$. Meanwhile, the GDR in the horizontal direction should be arranged within fracture angle and completely avoid being arranged red area outside the fracture line.

According to the above analysis, the optimal layout parameter of the GDR in the height direction is determined in the middle and lower part of the blue area and is arranged in central line of the blue area along the direction of the coal seam.

That is, the height range of the GDR is from $10.7 \mathrm{~m}$ to $32.8 \mathrm{~m}$ away from the coal seam roof, which is the middle of the blue region in the height direction in Figure 7. The GDR in the horizontal direction away ventilation roadway is in the range of $0 \mathrm{~m}$ to $35 \mathrm{~m}$. The specific layout of the GDR is shown in Figure 7.

5.2. Field Application Analysis. To further optimize the parameters of the GDR in Sima mine, gas drainage effect is monitored in different heights away from coal-seam roof in \#1207 working face and different horizontal distances away from the ventilation roadway in \#1211 working face in Sima mine.

5.2.1. Drainage Effect in \#1207 Working Face. The horizontal section of the GDR in \#1207 working face is between $26 \mathrm{~m}$ and $31 \mathrm{~m}$ away from the coal roof, and the horizontal distance is $35 \mathrm{~m}$ from the ventilation roadway. The layout and profile of GDR in \#1207 working face are shown in Figures 8 and 9.

The flow of GDR, pure gas content, and gas concentration are monitored for the different heights of GDR in the process of working face advancing. The relation between height of the GDR and gas data is shown in Figure 10.

The flow of the GDR and gas content are lower and more stable when the height of the GDR is below $13.0 \mathrm{~m}$. This is because the height of the GDR is low in the caving zone, and the gas drainage is mainly derived from coal falling area and low concentration gas area in caving zone. 
TABLE 3: Calculation results.

\begin{tabular}{lcccccc}
\hline Key stratum & $\beta\left(^{\circ}\right)$ & $i$ & $q(\mathrm{MPa})$ & $\sigma_{c}(\mathrm{MPa})$ & $\sigma_{p}(\mathrm{MPa})$ & $\sigma_{c} / \sigma_{p}$ \\
\hline First inferior key stratum & 87.8 & 1.75 & 392.23 & 26.0 & 4.29 & 0.165 \\
Second inferior key stratum & 87.2 & 7.22 & 130.37 & 67.9 & 0.35 & 0.005 \\
Main key stratum & 87.0 & 4.19 & 386.47 & 106.2 & 1.34 & 0.29 \\
\hline
\end{tabular}

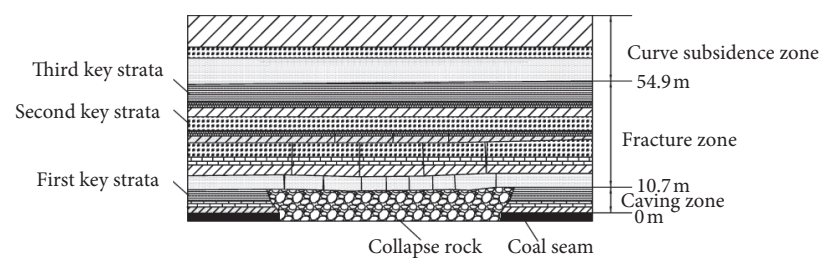

FIGURE 3: Distribution of fracture zone.

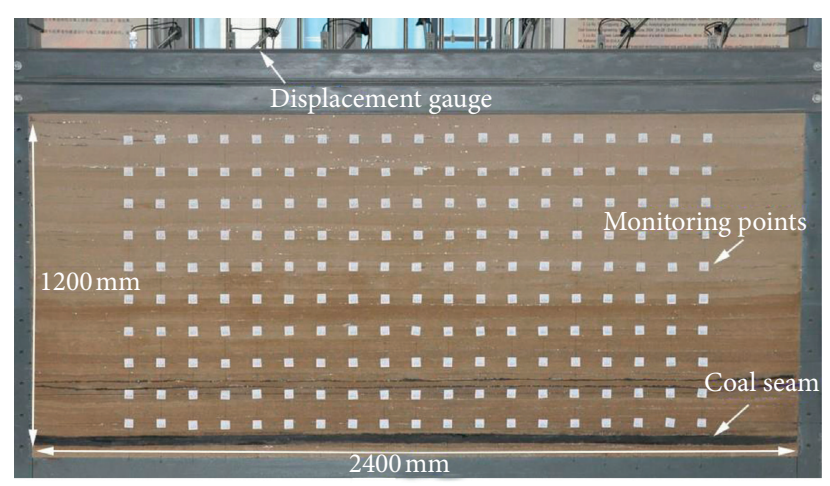

FIgURE 4: The model before excavation.

TABLE 4: Fracture angle of overburden roof.

\begin{tabular}{lcccc}
\hline Advancing distance & $60 \mathrm{~cm}$ & $90 \mathrm{~cm}$ & $120 \mathrm{~cm}$ & $150 \mathrm{~cm}$ \\
\hline Fracture angle in the mining side & $61^{\circ}$ & $63^{\circ}$ & $64^{\circ}$ & $60 \mathrm{~cm}$ \\
Fracture angle in the open-off cut side & $65^{\circ}$ & $66^{\circ}$ & $66^{\circ}$ & $58^{\circ}$ \\
\hline
\end{tabular}

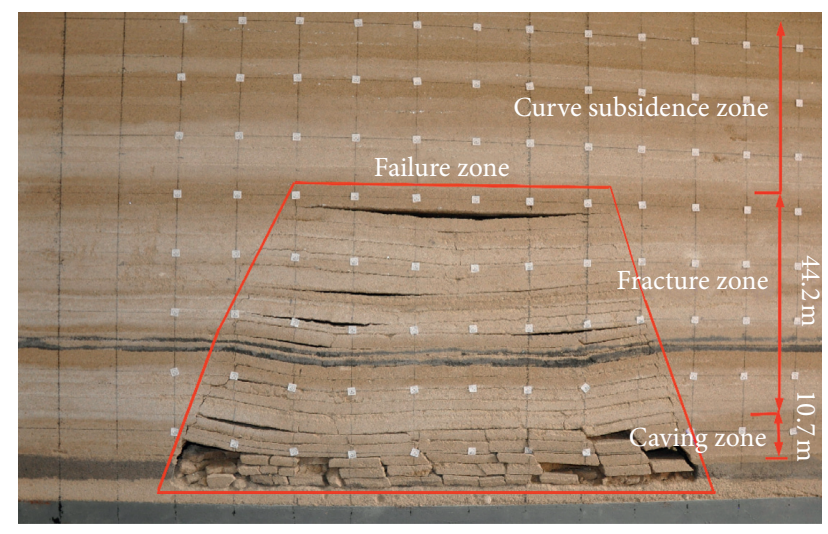

FIGURE 5: Distribution results of fracture zone.

When the height is from $13.0 \mathrm{~m}$ to $20.0 \mathrm{~m}$, the GDR is in fracture zone and the fractures are well developed. The highdensity gas is pumped into the GDR by negative pressure. Meanwhile, the gas concentration and pure gas content

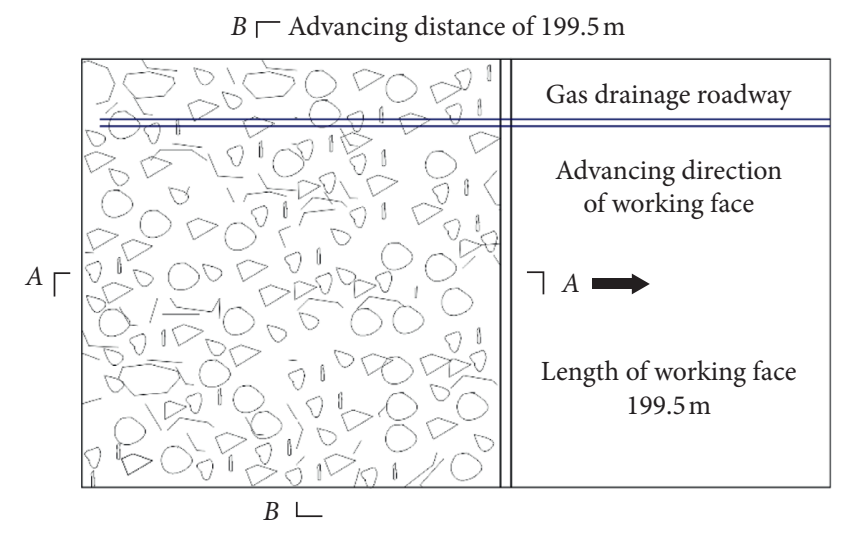

FIGURE 6: A-A profile.

increase with the increase of the height of GDR. When the height of the GDR is $19 \mathrm{~m}$, the gas drainage effects are best. The gas concentration is up to $2.99 \%$, and the pure gas content is $11.5 \mathrm{~m}^{3} / \mathrm{min}$. When the height exceeds $22.0 \mathrm{~m}$, the 


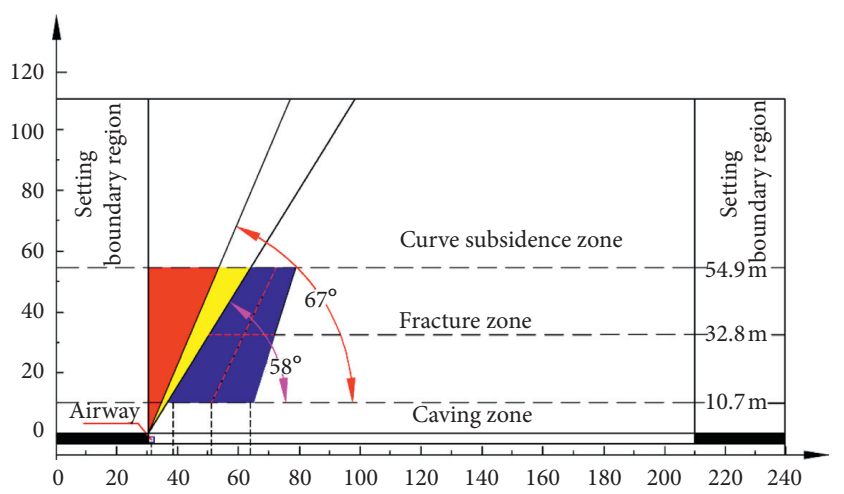

Figure 7: Layout of the gas drainage roadway.

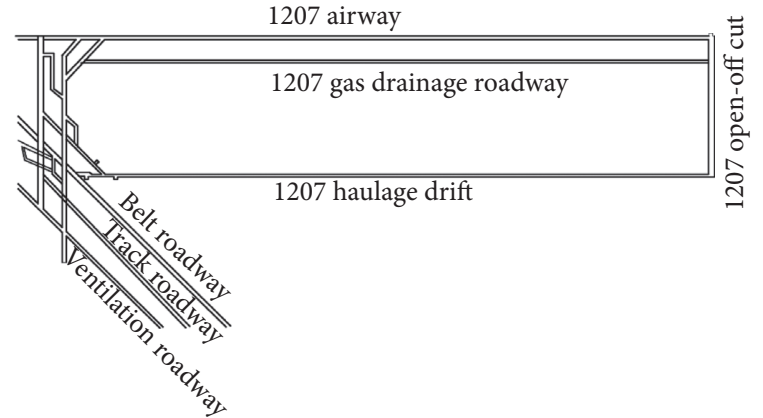

FIGURE 8: GDR layout in \#1207 working face.

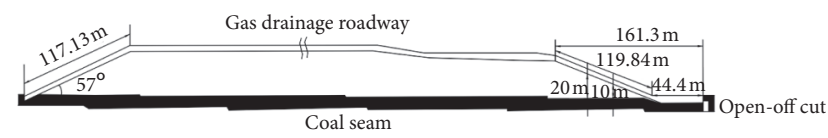

Figure 9: Profile of GDR.

pure gas content curve shows a downward trend and gradually stabilizes. The optimal scope of GDR is from $17.5 \mathrm{~m}$ to $22 \mathrm{~m}$ in the height direction.

5.2.2. Drainage Effect in 1211 Working Face. The strike length of 1211 working face is $220 \mathrm{~m}$. The GDR is located in the upper mudstone, and the distance is $15 \mathrm{~m}$ away from coal roof. The plane layout and gas drainage data are shown in Figures 11 and 12. When the horizontal distance between the GDR and the airway is below $13 \mathrm{~m}$, gas concentration and pure gas content slowly grow with horizontal distance increasing. Gas concentration and pure gas content rapidly grow when the distance is more than $13 \mathrm{~m}$. When the horizontal distance is $18 \mathrm{~m}$, the drainage effect is the best. The gas concentration is up to $1.75 \%$, and the pure gas content is $11.3 \mathrm{~m}^{3} / \mathrm{min}$. The curves decrease and gradually stabilize. The optimally horizontal distance of the GDR is from $17 \mathrm{~m}$ to $21 \mathrm{~m}$ away from airway.

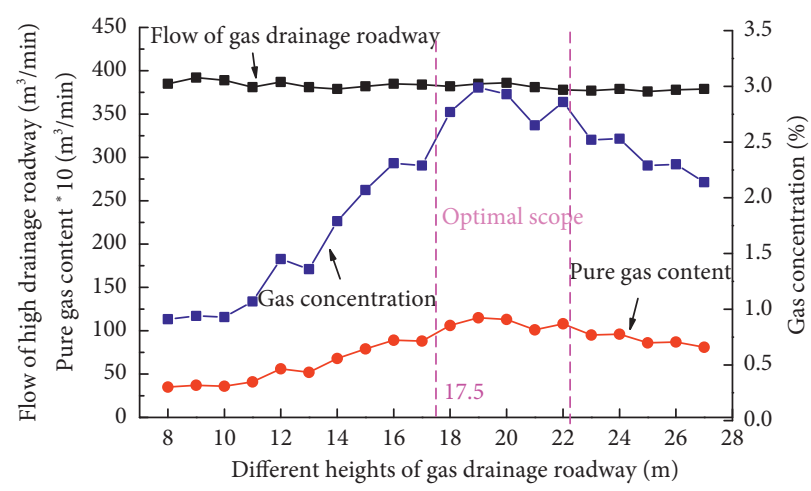

FIGURE 10: Drainage parameters versus height of the GDR in \#1207 working face.

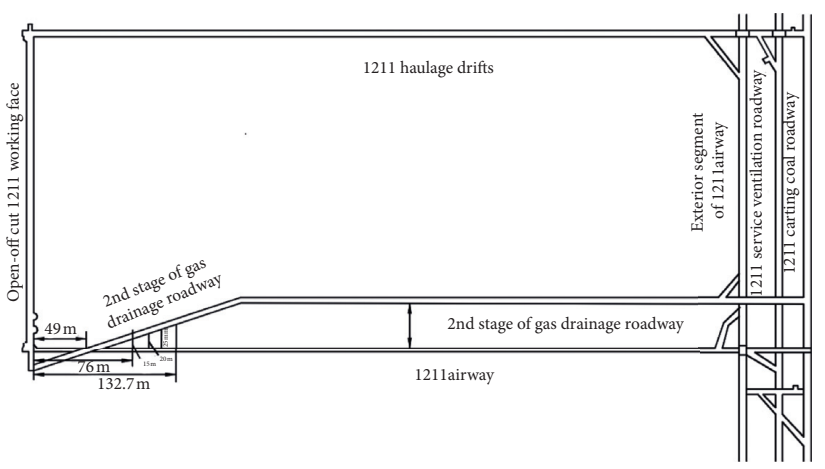

FIGURE 11: Layout of the GDR in 1211working face.

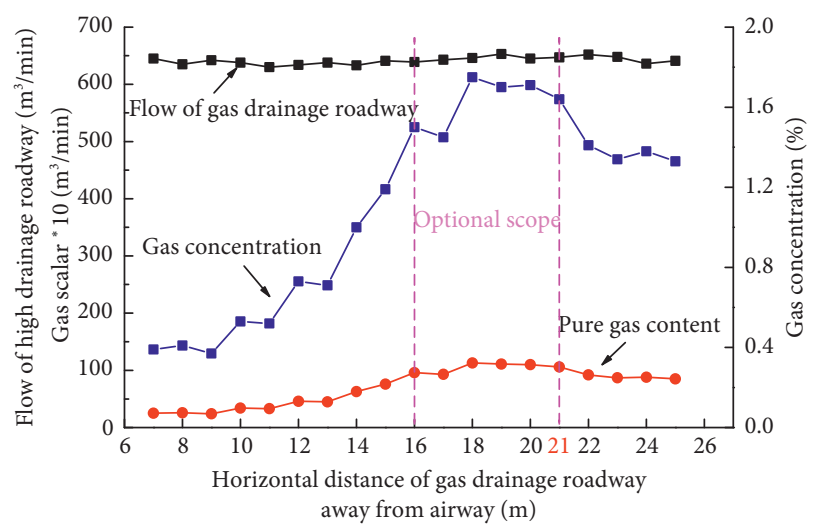

FIGURE 12: Drainage parameters versus the horizontal distance of the GDR in 1211working face.

\section{Conclusions}

Based on the engineering background of \#1207 working face in Sima mine, the analytical calculation method of fracture zone considering multiple factors is used to obtain the layout parameters of the GDR in the work. With the aid of scale modelling experiment results, the layout parameters of the GDR in Sima mine are determined. Meanwhile, the layout 
parameters of the GDR are optimized by monitoring the gas drainage effect in the field. The following conclusions are as follows.

(1) The height of fracture zone is obtained by the analytical calculation method considering multiple influence factors. The results show there are three key strata above the coal seam. The height of caving zone in Sima mine is $10.7 \mathrm{~m}$ away from the coal roof, and the height of the fracture zone is from $10.7 \mathrm{~m}$ to $54.9 \mathrm{~m}$.

(2) The results of analytical calculations and scale modelling experiment are applied to obtain the parameters of the GDR. We finally propose that the GDR of Sima mine should be arranged in the range of $10.7 \mathrm{~m}$ to $32.8 \mathrm{~m}$ from the coal seam in the height direction. The projection distance parallel to the direction of the coal seam is within the range of 0-35 $\mathrm{m}$ from the airway.

(3) Gas drainage effects in the field are monitored, and the optimal layout parameters of the GDR are proposed. The field analysis shows that the results obtained by analytical calculation and scale modelling experiment are reasonable. The optimal scope of the GDR is from $17.5 \mathrm{~m}$ to $22 \mathrm{~m}$ in the height direction. The optimally horizontal distance of the GDR is from $17 \mathrm{~m}$ to $21 \mathrm{~m}$ away from airway.

\section{Abbreviations}

M: Thickness of coal seam (m)

$h_{1}$ : Thickness of immediate roof $(\mathrm{m})$

$\left(k_{p}^{\prime}\right)$ : Residual expansion rate of rock $(\mathrm{m})$

$\sum h$ : Gross thicknesses between key strata and working face (m)

C: $\quad$ Recovery ratio (1)

$a$ : Length of working face $(\mathrm{m})$

$\alpha: \quad$ Fracture angle of overlying strata $\left({ }^{\circ}\right)$

$\sigma_{p}$ : Extrusion stress of occlusal area for fracture rock $(\mathrm{Pa})$

$h_{2}$ : Thicknesses of key strata $(\mathrm{m})$

$\sigma_{c}$ : Compressive strength of rock $(\mathrm{Pa})$

$R_{\mathrm{t}}$ : Tensile strength of key strata $(\mathrm{Pa})$

$q$ : Load of key strata. $\left(\mathrm{N} / \mathrm{m}^{3)}\right.$

$\varphi$ : $\quad$ Friction angle of rock $\left({ }^{\circ}\right)$

L: $\quad$ Fracture length $(\mathrm{m})$

$k$ : $\quad$ Proportional coefficient (1)

$\Delta: \quad$ Cavitation size (1)

$\beta$ : $\quad$ Allowed angle of subsidence $\left({ }^{\circ}\right)$.

\section{Data Availability}

The data used to support the findings of the study are included in this article.

\section{Conflicts of Interest}

The authors declare that they have no conflicts of interest.

\section{Acknowledgments}

This study was supported by The National Natural Science Foundation of China (No. 51274209).

\section{References}

[1] D. Ma, H. Duan, J. Liu, X. Li, and Z. Zhou, "The role of gangue on the mitigation of mining-induced hazards and environmental pollution: an experimental investigation," Science of the Total Environment, vol. 664, pp. 436-448, 2019.

[2] D. Ma, J. X. Zhang, H. Y. Duan et al., "Reutilization of gangue wastes in underground backfilling mining: overburden aquifer protection," Chemosphere, vol. 264, no. 1, Article ID 128400, 2021.

[3] T. A. Moore, "Coalbed methane: a review," International Journal of Coal Geology, vol. 101, no. 1, pp. 36-81, 2012.

[4] C. Wang, S. Yang, and X. Li, "Simulation of the hazard arising from the coupling of gas explosions and spontaneously combustible coal due to the gas drainage of a gob," Process Safety \& Environmental Protection, vol. 118, pp. 296-330, 2018.

[5] Y. Peng, C. Q. Ye, F. J. Sun et al., "Drainage gas recovery technology for high-sulfur gas wells by a canned ESP system," Natural Gas Industry B, vol. 5, no. 5, pp. 452-458, 2018.

[6] C. Liu, S. Li, and S. Yang, "Gas emission quantity prediction and drainage technology of steeply inclined and extremely thick coal seams," International Journal of Mining Science and Technology, vol. 28, no. 3, pp. 415-422, 2018.

[7] Q. D. Qu, J. L. Xu, R. L. Wu, W. Qin, and G. Z. Hu, "Threezone characterisation of coupled strata and gas behavior in multi-seam mining," International Journal of Rock Mechanics \& Mining Sciences, vol. 78, pp. 91-98, 2015.

[8] Q. Qu, H. Guo, and M. Loney, "Analysis of longwall goaf gas drainage trials with surface directional boreholes," International Journal of Coal Geology, vol. 156, pp. 59-73, 2016.

[9] Y. Liang, "Theory and practice of integrated coal production and gas extraction," International Journal of Coal Science \& Technology, vol. 2, no. 1, pp. 1-9, 2015.

[10] H. H. Liu, S. X. Sang, G. X. Wang, Y. M. Li, M. X. Li, and S. Liu, "Evaluation of the synergetic gas-enrichment and higher-permeability regions for coalbed methane recovery with a fuzzy model," Energy, vol. 39, no. 1, pp. 426-439, 2012.

[11] S. G. Li, H. Q. Shuang, and H. S. Wang, "Determining the rational layout parameters of the lateral gas drainage roadway serving for two adjacent working faces," International Journal of Mining Science and Technology, vol. 26, no. 5, pp. 795-801, 2016.

[12] D. Creedy and H. Tilley, "Coal-bed methane extraction and utilization," Journal of Power and Energy, vol. 217, no. 1, pp. 19-25, 2003.

[13] K. Noack, "Control of gas emissions in underground coal mines," International Journal of Coal Geology, vol. 35, pp. 57-83, 1998.

[14] Q. Q. Liu, Y. P. Cheng, H. F. Wang et al., "Numerical assessment of the influences of coal permeability and gas pressure inhomogeneous distributions on gas drainage optimization," Journal of Natural Gas Science and Engineering, vol. 45, pp. 797-811, 2017.

[15] S. Wang, X. Li, and D. Wang, "Void fraction distribution in overburden disturbed by longwall mining of coal," Environmental Earth Sciences, vol. 75, pp. 186-200, 2016. 
[16] H. Guo, C. Todhunter, Q. Qu, and Z. Qin, "Longwall horizontal gas drainage through goaf pressure control," International Journal of Coal Geology, vol. 150-151, pp. 276-286, 2015.

[17] H. C. Ding and C. Ma, "Numerical simulation and experiment analysis on goaf methane drainage of strike high-position tunnel," Journal of Safety Science and Technology, vol. 8, no. 5, pp. 5-10, 2012.

[18] L. Wang, Y. P. Cheng, F. H. An, H.-X. Zhou, S.-L. Kong, and W. Wang, "Characteristics of gas disaster in the Huaibei coalfield and its control and development technologies," Natural Hazards, vol. 71, no. 1, pp. 85-107, 2014.

[19] Y. P. Cheng, L. Wang, H. Y. Liu et al., "Definition, theory, methods, and applications of the safe and efficient simultaneous extraction of coal and gas," International Journal of Coal Science \& Technology, vol. 2, no. 1, pp. 52-65, 2015.

[20] P. Lu, P. Li, J. Chen, C. Zhang, J. Xue, and T. Yu, "Gas drainage from different mine areas: optimal placement of drainage systems for deep coal seams with high gas emissions," International Journal of Coal Science \& Technology, vol. 2, no. 1, pp. 84-90, 2015.

[21] S. G. Li, H. F. Lin, P. X. Zhao et al., "Dynamic evolution of mining fissure elliptic paraboloid zone and extraction coal and gas," Journal of China Coal Society, vol. 38, no. 8, pp. 1455-1462, 2014.

[22] L. Yuan, "Study on critical, modern technology for mining in gassy deep mines," Journal of China University of Mining and Technology, vol. 17, no. 2, pp. 226-231, 2007.

[23] D. Ma, H. Y. Duan, Q. Zhang et al., "A numerical gas fracturing model of coupled thermal, flowing and mechanical effects," Computers, Materials \& Continua, vol. 65, no. 3, pp. 2123-2141, 2020.

[24] J. Xu, X. Z. Wang, and W. T. Liu, "Effects of primary key stratum location on height of water flowing fracture zone," Chinese Journal of Rock Mechanics and Engineering, vol. 28, no. 2, pp. 380-385, 2009.

[25] M. S. Yi, W. B. Zhu, L. Li, X. Zhao, and X. Jialin, "Waterinrush mechanism and prevention for fourth panel roof in Bulianta coalmine," Journal of China Coal Society, vol. 33, no. 3, pp. 241-245, 2008.

[26] D. Ma, H. Y. Duan, X. B. Li, Z. H. Li, Z. Zhou, and T. B. Li, "Effects of seepage-induced erosion on nonlinear hydraulic properties of broken red sandstones," Tunnelling and Underground Space Technology, vol. 91, Article ID 102993, 2019.

[27] Z. Q. Wang, P. F. Li, L. Wang et al., "Method of division and engineering use of "three band" in the stope again," Journal of China Coal Society, vol. 38, pp. 287-293, 2013.

[28] Y. W. Lan, Mine Ground Pressure and Control, Jilin University Press, Jilin, China, 2015.

[29] M. G. Qian, X. X. Mao, and F. L. He, "Key block analysis of "masonry beam"structure in the mining field," Journal of China Coal Society, vol. 19, no. 6, pp. 557-563, 1994.

[30] X. X. Mao, "Stability analysis of main roof at the first pressure in the mining field," Journal of China University of Mining \& Technology, vol. 18, no. 3, pp. 88-92, 1989. 